\title{
The epidemiology of paediatric inflammatory bowel disease
}

\author{
M Cosgrove, R F Al-Atia, H R Jenkins
}

\begin{abstract}
A retrospective study of the incidence and prevalence of paediatric inflammatory bowel disease over an 11 year period was undertaken in South Glamorgan. Over this time the incidence of Crohn's disease more than doubled from 1.30 cases per 100000 childhood population per year in the period 1983-1988, to $3 \cdot 11$ cases per 100000 population per year in the period 1989-1993. In contrast, the incidence of ulcerative colitis remained the same throughout the study period at 0.71 per 100000 per year. In 1993 the prevalence of Crohn's disease in the childhood population was 16.6 per 100000 and of ulcerative colitis, 3.42 per 100000 . (Arch Dis Child 1996; 74: 460-461)
\end{abstract}

Keywords: Crohn's disease, ulcerative colitis, incidence, prevalence.

Most of the epidemiological studies on the incidence and prevalence of inflammatory bowel disease (IBD) relate to the adult population $^{12}$ and few studies have specifically addressed childhood IBD. Those that have report differing incidences and also differing proportions of Crohn's disease compared to ulcerative colitis in different countries. The only reported study from the United Kingdom was from Scotland, which showed a threefold rise in incidence of children with Crohn's disease over 16 years (1968-1983), from 0.66 to $2 \cdot 29$ per 100000 , compared to a marginal fall in ulcerative colitis, ${ }^{3}$ trends which are similar to those reported for adult IBD in Cardiff. ${ }^{12}$

As no previous studies on the incidence and prevalence of paediatric IBD in England and Wales have been reported, and in order to see if the increase in Crohn's disease found in other studies was also apparent in Wales, we carried out a retrospective study to determine the incidence of IBD in children (less than 16 years old) in a defined health district (South Glamorgan) between the years 1983 and 1993.

Department of Child Health, University Hospital of Wales, Cardiff

$M$ Cosgrove

R F Al-Atia

H R Jenkins

Correspondence to: Dr H R Jenkins, University Hospital of Wales,

Department of Child Health, Heath Park, Cardiff CF4 4XN.

Accepted 22 January 1996

We undertook a retrospective study to determine the incidence of IBD over an 11 year period (1983-1993) in children less than 16 years old at the time of diagnosis who resided in a defined health district (South Glamorgan). The childhood population figures in the district over this period were obtained from the Director of Public Health Medicine.

Considerable effort was made to ascertain all cases of Crohn's disease and ulcerative colitis through several different sources, and cross checks were made from records of hospital activity analysis (HAA), paediatric and adult gastroenterology clinics, and radiology, pathology, and dietetic departments in the three hospitals in South Glamorgan, and from endoscopy session records. The geography of South Glamorgan is such that it is most unlikely that patients would be referred to hospitals in adjacent health districts because of the distances involved. In addition there has not been a consultant paediatrician with a special interest in gastrointestinal disease in the adjacent health districts over the study period. We would have expected to identify cases diagnosed following private referral by the methods described above but as an additional check all general practitioners in South Glamorgan were sent letters asking them to report any patients aged less than 16 years with the diagnosis of IBD. Furthermore, the local and national patient/parent support groups (South Wales Association of Crohn's in Childhood, and Crohn's in Childhood Research Association) were asked for (and supplied) a list of their members resident in South Glamorgan.

Case notes of all children with IBD between 1983 and 1993 were thus obtained and the various diagnostic criteria confirmed. These diagnostic criteria included clinical features (abdominal pain, weight loss, and diarrhoea), radiological, endoscopic, and histological findings. Cases were classified as Crohn's disease if histology of intestinal specimens obtained surgically or endoscopically showed evidence of transmural inflammation with non-caseating granuloma, or if imaging revealed inflammation of the terminal ileum or discontinuous areas of inflammation, in combination with a typical clinical picture and increased blood inflammatory markers. The classification of ulcerative colitis was always made on histological evidence of mucosal inflammation with ulceration and crypt abscesses combined with the clinical picture.

With the knowledge of the numbers of the population aged less than 16 years over this time in the defined geographical area, the incidence and prevalence of Crohn's disease and ulcerative colitis were calculated. Ethical approval for the study was obtained from the local research ethics committee.

\section{Results}

The population in South Glamorgan of children less than 16 years varied only slightly around 90000 between the years 1983 and 1993. The medical notes of 60 patients whose records indicated a possible diagnosis of IBD 
over this period were reviewed by a consultant paediatric gastroenterologist (HRJ). Twenty eight children satisfied the diagnostic criteria for IBD, $21(75 \%)$ with Crohn's disease and seven $(25 \%)$ with ulcerative colitis. All cases reviewed were found to satisfy the diagnostic criteria detailed above. There was very little overlap with the cases previously documented by the adult gastroenterologists in Cardiff ${ }^{12}$ as the study periods were different. The median age at diagnosis was $12 \cdot 1$ years for Crohn's disease (range 6-16 years) and $12 \cdot 7$ years for ulcerative colitis (range 10-14 years).

Overall the incidence of Crohn's disease between the years 1983 and 1993 was $2 \cdot 21$ cases per 100000 per year. The incidence figures for each quinquennium of age were $2 \cdot 2$ cases per 100000 per year for age 5-10 years, and 4.3 cases per 100000 per year for age 10-15 years. The incidence increased over the study period from 1.30 cases $(95 \%$ confidence intervals $(\mathrm{CI}) 0.57,2.8)$ per 100000 population per year for 1983-1988 to 3.11 cases $(95 \%$ CI $1 \cdot 78,5 \cdot 36)$ per 100000 population per year for 1989-1993; the $95 \%$ CI values for the difference between the two periods were $-0.4,3.23(p=0.065)$. In contrast the incidence of ulcerative colitis remained at 0.71 cases per 100000 per year over the 11 year period.

In 1993 the prevalence of paediatric IBD was 20.02 per 100000 population, with that of Crohn's disease being 16.6 per 100000 and ulcerative colitis 3.42 per 100000 children.

\section{Discussion}

This is the first study from England and Wales to report the incidence and prevalence of IBD in the paediatric age group. Our results show similar trends to those reported on the epidemiology of adult IBD in the city of Cardiff, which accounts for about $75 \%$ of the population of South Glamorgan. The incidence of Crohn's disease in Cardiff has increased more than fourfold over 25 years, and the most recently published data showed that this trend was continuing in $1985^{1}$ with the incidence figure of 8.3 per 100000 per year being over twice the figure we found for the second half of our study. In contrast, the incidence of ulcerative colitis altered very little over 20 years from 1968-1987,2 with figures almost 10 times those we report in children.

The only published epidemiological study in children in the United Kingdom is from Scotland and showed a threefold rise in incidence of Crohn's disease, from 0.66 in 1968 to 2.29 per 100000 per year in 1983 , while over the same period the incidence of ulcerative colitis did not show a significant change, from 1.91 per 100000 in 1968 to 1.51 per 100000 in $1983 .{ }^{3}$ Our study of Welsh children also shows a marked increase in the incidence of Crohn's disease with, in recent years, a predominance of Crohn's disease over ulcerative colitis. The ratio of children diagnosed as having Crohn's disease compared to ulcerative colitis in the latter half of our study $(4 \cdot 4: 1)$ was very similar to that found in a prospective epidemiological study of IBD in the Nord-Pas-deCalais region of France, which showed an incidence of 2.07 per 100000 children per year for Crohn's disease and 0.46 per 100000 children per year for ulcerative colitis. ${ }^{4}$

However, these ratios contrast with the findings from two studies in the mid-1980s on children in Scandinavia. A Norwegian study found the annual incidence of Crohn's disease in 1984-1985 was 2.5 per 100000 per year, whereas the incidence of ulcerative colitis was 4.3 per 100000 per year. ${ }^{5}$ In Sweden over the same two years the incidence was reported to be much lower, but also showed a predominance of ulcerative colitis over Crohn's disease. ${ }^{6}$ The reasons for these variations and for the reported recent increase in the incidence of Crohn's disease in some areas are not known.

This study reveals a marked increase in the incidence of Crohn's disease in children over the 11 year period, such that Crohn's disease is now much more common than ulcerative colitis in the paediatric population of South Glamorgan. The reasons for these trends are not known and regional studies in Wales and other regions in England would be helpful to see if this trend has occurred in other areas of the United Kingdom.

The authors gratefully acknowledge the assistance with statistical analysis given by Mr Frank Dunstan, Lecturer in the Department of Medical Computing and Statistics, University of Wales College of Medicine.

1 Rose JDR, Roberts GM, Williams G, Mayberry JF, Rhodes J. Cardiff Crohn's disease jubilee: the incidence over 50 years. Gut 1988; 29: 346-51.

2 Srivastava ED, Mayberry JF, Morris TJ, et al. Incidence of ulcerative colitis in Cardiff over 20 years: $1968-87$. Gut 1992; 33: 256-8.

3 Barton JR, Gillon S, Ferguson A. Incidence of inflammatory bowel disease in Scottish Children between 1968 and 1983; marginal fall in ulcerative colitis, threefold rise in Crohn's disease. Gut 1989; 30: 618-22.

4 Gottrand F, Colombel JF, Moreno L, Salomez JL, Farriaux $\mathrm{JP}$, Cortot A. Incidence of inflammatory bowel diseases in children in the Nord-Pas-de-Calais region. Arch Fr Pediatr 1991; 48: 25-8.

5 Olafsdottir EJ, Fluge G, Haug K. Chronic inflammatory bowel disease in children in Western Norway. $\mathcal{F}$ Pediatr Gastroenterol Nutr 1989; 8: 454-8.

6 Hildebrand H, Fredrikzon B, Holmquist L, Kristiansson B, Lindquist B. Chronic inflammatory bowel disease in children and adolescents in Sweden. $\mathscr{f}$ Pediatr Gastroenterol Nutr 1991; 13: 293-7. 